\title{
Affective norms of 875 Spanish words for five discrete emotional categories and two emotional dimensions
}

\author{
J. A. Hinojosa • N. Martínez-García • C. Villalba-García • \\ U. Fernández-Folgueiras • A. Sánchez-Carmona • \\ M. A. Pozo • P. R. Montoro
}

Published online: 5 March 2015

(C) Psychonomic Society, Inc. 2015
A growing body of research has indicated that emotional content modulates language comprehension and production (e.g., Citron, 2012; Herbert, Junghofer, \& Kissler, 2008; Hinojosa, Méndez-Bértolo, Carretié, \& Pozo, 2010; Kissler, Assadollahi, \& Herbert, 2006; Scott, O’Donnell, \& Sereno, 2012). These effects have been reported using a wide variety of methodologies, experimental paradigms, and tasks. In this sense, differences in the processing of neutral and emotionally laden words have been found in behavioral, event-related potential, functional magnetic resonance (fMRI), and positron emission tomography (PET) studies with a variety of tasks, including lexical decision, the emotional Stroop, emotional category judgments, or silent reading (Dijksterhuis \& Aarts, 2003; Estes \& Verges, 2008; González-Villar, Triñanes, Zurrón, \& Carrillo-de-la-Peña, 2014; Hinojosa, MéndezBértolo, \& Pozo, 2010; Robinson, Storbeck, Meier, \& Kirkeby, 2004; Schacht \& Sommer, 2009; Straube, Sauer, \& Miltner, 2011). Typically, a processing advantage for emotional as compared with neutral words is observed at several processing stages. In this sense, relative to neutral words, emotional words seem to engage additional attentional resources that speed their processing (Hofmann, Kuchinke, Tamm, Võ, \& Jacobs, 2009; Kissler \& Herbert, 2013; Kissler, Herbert, Peyk, \& Junghofer, 2007; Kousta, Vinson, \& Vigliocco, 2009; Méndez-Bértolo, Pozo, \& Hinojosa, 2011b). However, some studies have reported slower recognition of negative than of neutral and/or positive words (Algom, Chajut, \& Lev, 2004; Estes \& Adelman, 2008; Estes \& Verges, 2008; Kuperman, Estes, Brysbaert, \& Warriner, 2014). The processing of emotional words also modulates activity in several cortical and subcortical regions, including the amygdala, as well as the prefrontal and visual cortices (Isenberg et al., 1999; Kuchinke et al., 2005; Nakic, Smith, Busis, Vythilingam, \& Blair, 2006). Some evidence has suggested that emotional effects on word processing may also be observed in more complex linguistic contexts, such as 
sentences or texts. For instance, it has been shown that emotional aspects of stories activate the amygdala and the ventromedial prefrontal cortex (Ferstl, Rinck, \& von Cramon, 2005). Also, affective content modulates agreement relations between the constituents of a sentence, attachment decisions for relative clauses, and lexico-semantic processes related to word meaning integration in sentences (Fraga, Piñeiro, Acuña-Fariña, Redondo, \& García-Orza, 2012; Hinojosa, Albert, Fernández-Folgueiras, et al., 2014; Holt, Lynn \& Kuperberg, 2009; Martín-Loeches et al., 2012).

Two main theoretical approaches have been proposed to best characterize emotions, each of which has received empirical support: namely, the two-dimensional circumplex model and the discrete emotion theory. The two-dimensional circumplex model claims that emotions arise from two independent neurophysiological systems (Barrett \& Russell, 1999; Russell, 1980, 2003). The dimension of valence ranges from pleasant to unpleasant, whereas the dimension of arousal describes the degree of activation from calming to exciting. From a different perspective, the so-called discrete-emotion theories assume that all emotions can be derived from a limited number of innate and universal affective states, such as happiness, anger, sadness, fear, and disgust (Ekman, 1992, 1999; Panksepp, 1998). Accordingly, independent neural mechanisms would underlie every discrete basic emotion. Although this framework has been extensively investigated in studies that have explored the processing of facial expressions (e.g., Eimer \& Holmes, 2002; Eimer, Holmes, \& McGlone, 2003), the discrete-emotion approach has received relatively less attention in language research. However, some evidence points to the existence of categorical effects in the processing of emotional words. Along this line, the results of several studies have revealed shorter lexical decision times for happy than for both fearful and neutral words (Briesemeister, Kuchinke, \& Jacobs, 2011a, 2011b). Therefore, some authors have suggested that additional efforts with combined approaches will be needed in order to provide us with a more comprehensive view of emotional effects on word processing (Briesemeister et al., 2011b; Stevenson, Mikels, \& James, 2007).

Research concerning the effects of emotional content on language processing has used words from norm lists. For instance, the Affective Norms for English words (ANEW; Bradley \& Lang, 1999), which provides ratings for 1,034 words in the dimensions of valence, arousal, and dominance, is the most widely used corpus in English. This corpus has been adapted to several languages, including Spanish (Redondo, Fraga, Padrón, \& Comesaña, 2007), European Portuguese (Soares, Comesaña, Pinheiro, Simões, \& Frade, 2012), and Italian (Montefinese, Ambrosini, Fairfield, \& Mammarella, 2014). Furthermore, as Table 1 shows, other databases also exist in different languages, such as English (Warriner, Kuperman, \& Brysbaert, 2013), French (Monnier
\& Syssau, 2014), German (Võ, Jacobs, \& Conrad, 2006), and Dutch (Moors et al., 2013).

Five Spanish-language databases are currently available with affective scores for words. The first was published by Campos and Astorga (1988). It includes 300 words rated by 100 young adults in pleasantness (on a 9-point scale) and abstractness (on a 7-point scale). Redondo, Fraga, Comesaña, and Perea (2005) drew up another affective database of 478 words that were rated by 360 participants for valence and arousal with the Self-Assessment Manikin (SAM; Bradley \& Lang, 1994). This study also provided scores taken from the LEXESP (Sebastián-Galles, Martí, Carreiras, \& Cuetos, 2000) for several subjective psycholinguistic variables whenever they were available, including familiarity, concreteness, and imageability. A third database is a Spanish adaptation of the ANEW (Redondo et al., 2007). Using the SAM, ratings for valence, arousal, and dominance were collected for 1,034 words from 720 young adults. Again, scores for familiarity, concreteness, and imaginability were taken from the LEXESP. A fourth database, compiled by Pérez-Dueñas, Acosta, Megías, and Lupiáñez (2010), provides ratings for 238 nouns. These words were assessed by 252 participants for valence (on a 9-point scale, ranging from -5 very negative to 5 very positive), arousal (on a 10-point scale), as well as relevance for anxiety, depression, and anger (also on a 10-point scale). Finally, Ferré, Guasch, Moldovan, and Sánchez-Casas (2012), reported ratings from 504 participants for valence and arousal (using the SAM), as well as for familiarity and concreteness (on a 9-point scale). Scores were collected for 380 words belonging to the semantic categories of animals, objects, and people.

These databases have proven to be invaluable for researches interested in affective language. Nonetheless, as experimental evidence has accumulated, new corpora are needed to include modulating variables that have not been considered in the current norm lists. This allows us to further extend our knowledge about the mechanisms involved in the processing of affective content in linguistic stimuli. Our main aim here was therefore to generate a database of Spanish words suitable for investigating effects of emotional features in language processing. We collected affective norms for a new set of Spanish words that were not included in the prior Spanish databases by Redondo and collaborators (2007) or Ferré, Guasch, Moldovan, and Sánchez-Casas (2012). Thus, our corpus also provides additional materials that may be useful when researchers can not find enough stimuli in the current available databases to prevent possible effects of word repetition (Ferré et al., 2012).

In addition, we also aimed to complement previous databases in several methodological and theoretical respects. First, words were rated in the two main affective dimensions (valence and arousal), as well as in five discrete emotional categories (happiness, anger, sadness, fear, and disgust). As we 


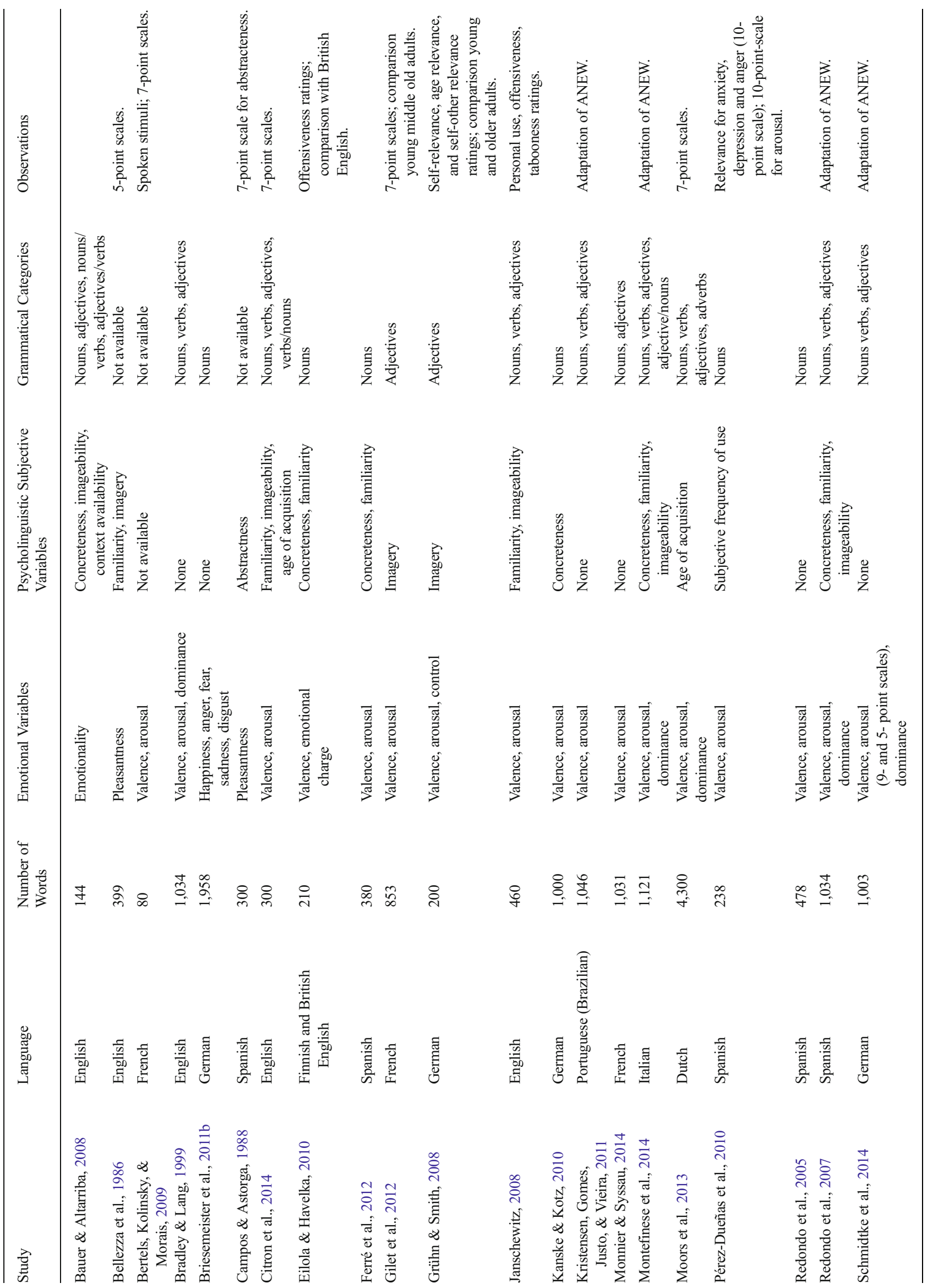




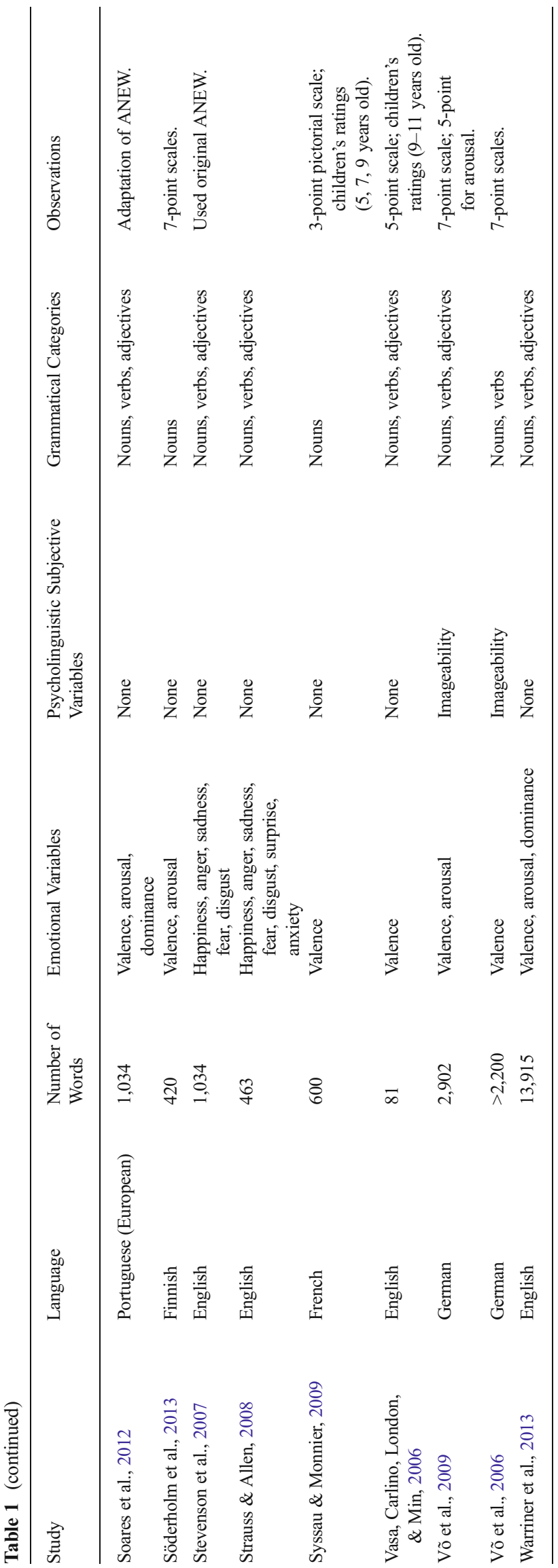

have already mentioned, in light of recent evidence suggesting a role of discrete emotions in word processing (Briesemeister et al., 2011a, 2011b; Briesemeister, Kuchinke, \& Jacobs, 2014; Silva, Montant, Ponz, \& Ziegler, 2012), studies using emotional words as stimuli would benefit not only from a dimensional but also from a categorical characterization of the words. Norms for discrete emotions, however, have not yet been made available in Spanish (for norms in German, see Briesemeister et al., 2011b; for norms in English, see Stevenson et al., 2007, and Strauss \& Allen, 2008; see also Stevenson \& James, 2008, for ratings of discrete emotional categories for the International Affective Digitized Sounds).

Second, some reports have observed that grammatical word class influences emotion effects in word comprehension, with a processing advantage for emotional nouns and adjectives relative to verbs (Palazova, Mantwill, Sommer, \& Schacht, 2011; Schacht \& Sommer, 2009). These findings suggest that additional research is needed that will explore the role of grammatical category in relation to other variables impacting the processing of affective content. However, some published norm lists in Spanish have included only nouns (Ferré et al., 2012) or have consisted of less than $10 \%$ verbs (Redondo et al., 2007). In the present corpus, we report ratings for 304 verbs (34.7\%), 301 nouns (34.4\%), 126 adjectives (14.4\%), and 144 words that could be considered as either an adjective or a noun (16.5\%). Thus, we provide a set of stimuli that could be suitable to further explore word class effects on the processing of emotional words.

Third, accumulating evidence has suggested that emotion content is a crucial variable in the representation of abstract concepts. In these sense, it has been reported that emotional content may exert a greater influence in the processing of abstract than of concrete words (Hinojosa, Albert, LópezMartín, \& Carretié, 2014; Kanske \& Kotz, 2007; Kousta, Vigliocco, Vinson, Andrews, \& Del Campo, 2011; Palazova, Sommer, \& Schacht, 2013; Vigliocco et al., 2014). Thus, given the importance of this variable, participants rated every word in the concreteness dimension. This would complement previous norm lists in which concreteness values for 380 nouns were collected (Ferré et al., 2012) or that had just reported concreteness ratings for a subset of words (Redondo et al., 2007). In addition, frequency of use, taken from LEXESP (Sebastián-Gallés et al., 2000), and word length (number of letters and syllables) were reported.

\section{Method}

Participants

Values from 660 native Spanish participants (507 females, 153 males; mean age $=23.2$ years, $S D=7.2$ ) were collected. Most of them were students from three universities of Madrid 
(Complutense University, Autónoma University, and Rey Juan Carlos I University), but several nonstudent participants also took part in the study. The sample included volunteer participants from different levels of educational attainment: high school degree (15.6\%), undergraduate studies (67.7\%), graduate studies $(9.4 \%)$, and doctorate $(7.7 \%)$.

\section{Materials and procedure}

The word set contained 875 Spanish words. The words were selected from the LEXESP (Sebastián-Gallés et al., 2000) and from prior studies by our group (Hinojosa, Carretié, Valcárcel, Méndez-Bértolo, \& Pozo, 2009; Hinojosa, Méndez-Bértolo, \& Pozo, 2010, 2012; Hinojosa et al., 2015; Méndez-Bértolo, Pozo, \& Hinojosa, 2011a). The selection of the words attempted to include as many words as possible with a marked affective value in addition to neutral words. The only constraint was that these words were not included in the Spanish Adaptation of the ANEW (Redondo et al., 2007) or in the database by Ferre and collaborators (2012), with the exception of 16 and 11 words, respectively. Although one of our main purposes was to collect norms for a new set of words, this procedure would allow for testing the reliability of scores for a small set of words across studies. The whole 875 -word set was divided into 21 lists of 40 words and one list of 35 words. It was decided to use an online survey procedure, owing to the benefits that it brings in speed and wideness of distribution (Couper, 2000). The surveys were created using the SurveyMonkey Web software. The URL links were randomly distributed among our sample. Ratings from 30 participants were collected for each word in every list.

Upon accessing the questionnaire, participants found an initial page in which they answered a few demographic questions (age, sex, and level of educational attainment). Every effort was made to provide clear instructions here. In this sense, instructions for valence, arousal, and concreteness ratings were an adaptation of those used in a prior study by Ferré and collaborators (2012), and the procedure used in Stevenson and collaborators' (2007) study was adapted for discrete categories. These instructions are presented in the Appendix. Participants were informed about the time estimated for completion (which was about 20-25 min), as well as a statement about data confidentiality and about the purposes of the research. We also provided an e-mail contact in case they had any questions or would like to request more details about our research (as was suggested in Burke \& James, 2006). Finally, they were informed that there were no right or wrong answers and were encouraged not to think a lot about their ratings.

The following two pages contained each the list of 40 words, presented at the center of the screen, using Helvetica 14-point bold font. On one of the pages, the valence, arousal, and concreteness 9-point scales were presented under each word, as had been done in several studies published in this field (e.g., Ferré et al., 2012; Redondo et al., 2007; Võ et al., 2006). On the other page, the five basic emotions (happiness, anger, sadness, fear, and disgust) were presented with a 5point scale below each word, with 1 being not at all and 5 being extremely (Stevenson et al., 2007). Five-point scales had been used in previous studies that collected word scores for discrete dimensions in either English (Stevenson et al., 2007) or German (Briesemeister et al., 2011b). For each word, we provided a response option labeled "I don't know the meaning" (mean responses per word $=0.25, S D=1.07$ ).

It is worth noting that the order of presentation of the words on each page, the order of the scales for each word for a given participant, as well as the order of appearance of the two wordrating pages was randomized in all of the questionnaires. Furthermore, it was set that once the answers to a page had been submitted, participants could not go back to change their ratings. Each page began with a header that included clear instructions for the rating scales on that page. In the case of the scales of valence and arousal, such instructions included a pictorial depiction of the SAM. The SAM is a widely used tool in the assessment of the affective properties of stimuli. For the valence dimension, the SAM ranges from a smiling to a frowning figure, whereas it ranges from an excited to a relaxed figure for the arousal dimension (Bradley \& Lang, 1994).

\section{Results and discussion}

Table 2 shows a general overview of the database, with descriptive statistics for valence, arousal, and concreteness, as well as for each of the five discrete emotions and the psycholinguistic variables. The word list resulting from the rating procedure can be accessed as supplemental materials, from www.dropbox.com/s/o6dpw3irk6utfhy/Hinojosa $\% 20$ et $\%$ 20al_Supplementary\%20materials.xlsx?dl=0.

We first will explore the reliability of the ratings of every affective dimension and discrete emotion, as well as the concreteness scores. Thereafter, we will report our analyses of the associations between the valence and arousal ratings, and between the affective dimensions and discrete emotions. Finally, the relationship between the affective variables and the psycholinguistic characteristics included in our database will be considered.

\section{Reliability}

The reliability of the ratings of all the variables that were included in the database was estimated by using the splithalf intergroup procedure. For each version of the questionnaire, participants were randomly divided into two subgroups of equal size. Pearson correlations were calculated between participants' ratings for the two affective dimensions (i.e., 
Table 2 Descriptive stimulus characteristics

\begin{tabular}{llllllllllll}
\hline & Valence & Arousal & Happiness & Anger & Sadness & Fear & Disgust & Concreteness & Frequency & Length (letters) & Length (syllables) \\
\hline Mean & 4.77 & 5.52 & 2.29 & 1.92 & 2.02 & 2.14 & 1.72 & 6.03 & 20.78 & 7.64 & 3.17 \\
SD & 1.49 & 1.96 & 0.82 & 0.85 & 0.90 & 0.97 & 0.82 & 2.04 & 45.76 & 1.99 & 0.87 \\
Minimum & 1.1 & 1.73 & 1 & 1 & 1 & 1 & 1 & 2.07 & 0.18 & 2 & 1 \\
Maximum & 8.67 & 8.29 & 4.97 & 4.83 & 4.93 & 4.7 & 4.77 & 8.67 & 487.27 & 14 & 6 \\
Range & 7.57 & 6.56 & 3.97 & 3.83 & 3.93 & 3.7 & 3.77 & 6.6 & 487.1 & 12 & 5 \\
\hline
\end{tabular}

valence and arousal), the five discrete emotions (i.e., happiness, anger, sadness, fear, and disgust), and the concrete dimension. The corrected correlations using the SpearmanBrown formula were positive and highly significant. For the emotional dimensions, the mean correlation values were $r=$ .89 for arousal (ranging from $r=.73$ to .99 ) and $r=.94$ for valence (ranging from $r=.77$ to .99 ). This finding agrees with previous reports that showed greater variability for arousal than for valence scores (Eilola \& Havelka, 2010; Monnier \& Syssau, 2014; Moors et al., 2013; Redondo et al., 2007). High correlations were also observed for the discrete emotions, with mean values of $r=.97$ for happiness (ranging from $r=.88$ to .99), $r=.97$ for anger (ranging from $r=.95$ to .99), $r=.97$ for sadness (ranging from $r=.92$ to .99 ),$r=.96$ for fear (ranging from $r=.90$ to .99 ), and $r=.96$ for disgust (ranging from $r=$ .90 to .98$)$. Thus, variability was greater when participants had to score affective dimensions than when they were instructed to rate discrete emotions, with only subtle differences existing among the discrete emotion categories. Finally, we found a strong correlation for concreteness, with a mean of $r=.88$ (ranging from $r=.76$ to .95 ).

To further examine the generalizability of our ratings of the affective dimensions (there were no prior ratings for discrete emotions in Spanish), we correlated them with the scores from previous studies. Our data contained 16 words in common with Redondo and collaborators (2007) and 11 words that had previously been scored in Ferré and coworkers' (2012) study. For the valence dimension, strong correlations were found ( $r=.99$, with Redondo et al., 2007; $r=.98$, with Ferré et al., 2012). Also, high positive correlations were observed for the arousal dimension ( $r=.98$, with Redondo et al., 2007; $r=.74$, with Ferré et al., 2012). Thus, it seems likely that the norms collected in the present study may generalize to those obtained in previous work and are suitable to be used for the selection of stimuli in language and affective research.

Relationship between the valence and arousal dimensions

As in previous studies, we carried out regressions analyses with Emotional Valence as the independent factor and Arousal as the dependent factor (e.g., Ferré et al., 2012; Monnier \& Syssau, 2014). The linear and quadratic models were tested separately. A high quadratic relation between valence and arousal was observed $[R=.57, F(2,872)=$ $205.75, p<.0001]$, with the quadratic relation accounting for $32.1 \%$ of the variance. The quadratic model outperformed the simpler linear model, which, although significant, explained only $2.3 \%$ of the variance $[R=.16, F(2,873)=$ $20.2, p<.0001]$. Figure 1 shows the locations of the 875 words ratings in the two-dimensional affective space. In line with the findings of prior studies that have provided emotional ratings for words in different languages, the boomerangshaped distribution observed in Fig. 1 indicates that highly pleasant and unpleasant words were rated as being the most arousing stimuli, whereas items with low positive and negative ratings were perceived as being the least arousing (Bradley \& Lang, 1999; Eilola \& Havelka, 2010; Ferré et al., 2012; Kanske \& Kotz, 2010; Monnier \& Syssau, 2014; Montefinese et al., 2014; Redondo et al., 2007; Soares et al., 2012; Võ et al., 2009).

The association between valence and arousal was further examined by classifying each of the words in the database as being positive, negative, or neutral. Items were distributed according to the same criteria used in prior studies (Ferré et al., 2012; Monnier \& Sussau, 2014). Thus, words with values of valence ranging from 1 to 4 were considered negative $(M=2.37, S D=0.73)$, words scored between 4 and 6 were classified as neutral $(M=4.93, S D=0.51)$, and words ranging from 6 to 9 were considered positive $(M=7.29, S D=$ 0.67). According to this procedure, we identified 337 negative (38.43\% of the corpus; e.g., ansiedad, "anxiety"), 231 neutral (38.43\%; e.g., recolectar, "to collect"), and 307 positive ( $35.12 \%$; divertido, "funny") words. Thereafter, we explored the relation between the valence and arousal scores for the negative and positive words, taken separately. A significant negative correlation between valence and arousal was observed for negative words $(r=-.37, p<.0001)$, indicating that the most negative words were also those with the highest ratings in the arousal dimension (e.g., disparar, "to fire"). Regarding positive words, we found a significant positive correlation $(r=.25, p<.0001)$, suggesting that the most positive words were also the most arousing (e.g., besar, "to kiss"). These findings agree with previous reports (e.g., Monnier \& Syssau, 2014; Schmidtke, Schröder, Jacobs, \& Conrad, 2014). However, in the present study the correlation between valence and arousal showed a steeper slope for negative than for 


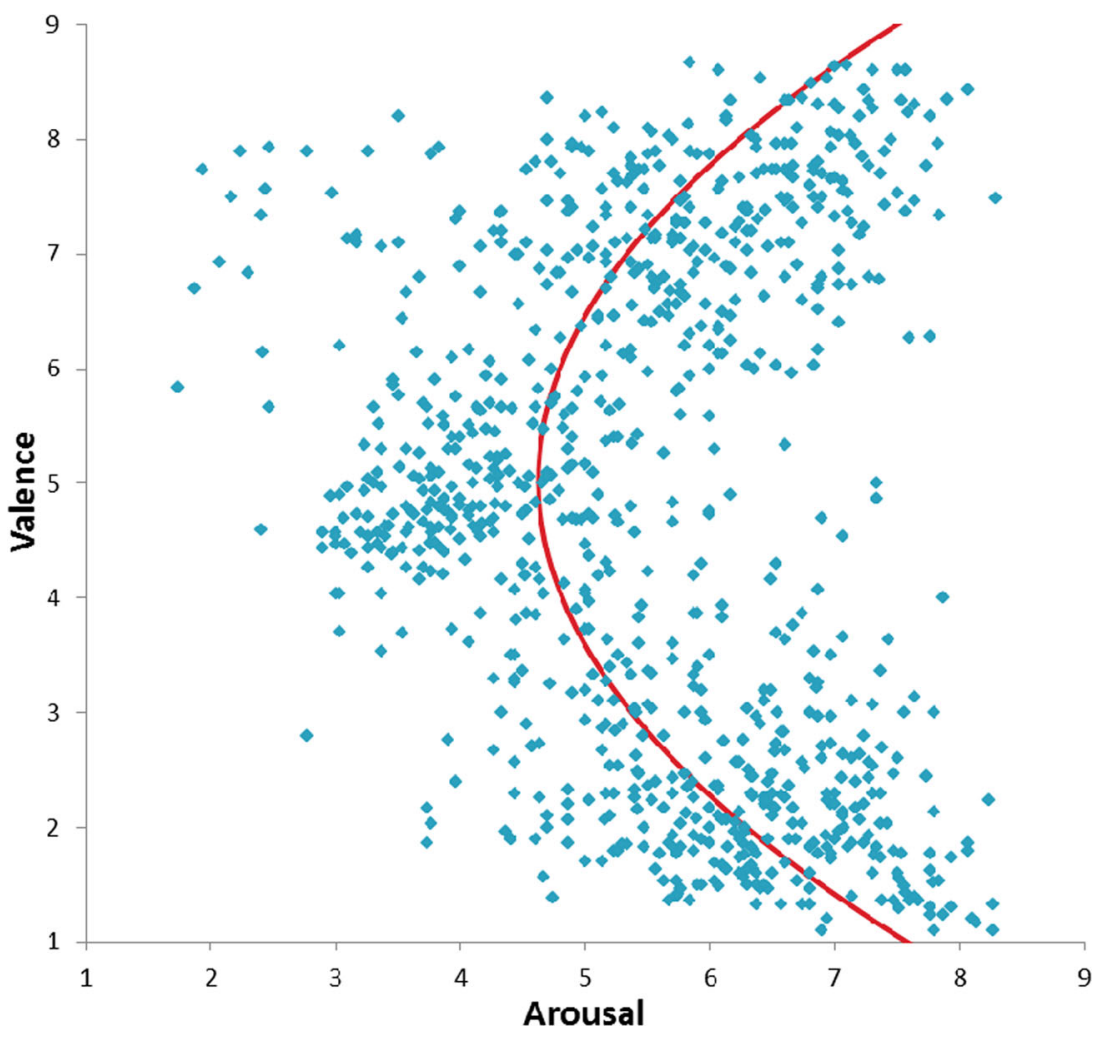

Fig. 1 Distribution of scores for the 875 words in the affective space defined by valence and arousal, for the total sample

positive words. Thus, we contrasted the arousal scores for the negative and positive words in a $t$ test and found that they were different $[t(306)=-4.37, p<.0001]$. In agreement with prior research (e.g., Citron, Weekes, \& Ferstl, 2014; Ferré et al., 2012), this result reflects the fact that positive words were more distributed around the arousal dimension (range: 1.87$8.29, M=5.75, S D=1.26$ ) than were negative words (range: $2.77-8.27, M=6.15, S D=1.02)$. As has been suggested, positive stimuli are associated with feelings of safety, so they are not necessarily high in arousal (e.g., "peace," "relax"), whereas negative stimuli may reflect a dangerous event that requires a quick response (Citron et al., 2014; Lang, Bradley, $\&$ Cuthbert, 1990).

Relationship between affective dimensions and discrete emotions

Additionally, we carried out general correlational analyses with the discrete emotion scores and ratings in the valence and arousal dimensions for every word. Given the high number of comparisons that we tested (i.e., 55), we report results that were significant at the Bonferroni-corrected $\alpha$ value of $.05 / 55 \approx .0009$ (see Montefinese et al., 2014, for a similar procedure). Table 3 shows the results of these analyses. In line with prior reports, we observed a highly significant positive correlation between each of the four negative emotional categories and arousal, as well as between scores in happiness and valence. Negative correlations existed between negative discrete emotions and valence, and between happiness and the other emotional categories.

Additional analyses were conducted to further investigate the relationships between affective dimensions and discrete emotions. These analyses were limited to words with scores higher than 2.5 in a given emotional category, which were classified as denoting either happy $(M=3.8, S D=0.59)$, angry $(M=3.71, S D=0.56), \operatorname{sad}(M=3.79, S D=0.59)$, fear $(M=$ $3.81, S D=0.58)$, or disgusting $(M=3.80, S D=0.67)$ emotions. Those words with ratings higher than 2.5 in more than one emotional category ( 95 words, or $10.85 \%$ : 40 words, $4.57 \%$, in two categories; 31 words, $3.54 \%$, in three categories; and 24 words, $2.74 \%$, in four categories) were ascribed to the category with the highest score. This resulted in 307 words being associated with happy ( $35.1 \%$ of the database; e.g., infancia, "childhood"), 84 words with angry (9.6\%; e.g., furia, "fury"), 87 with sad (9.9 \%; e.g., fallecer, "to perish"), 114 with fearful (13\%; e.g., abismo, "abyss"), and 30 with disgusting (3.4\%; e.g., repulsive, "repulsive") concepts. As is shown in Table 4, ratings for those words belonging to four of the five discrete emotions showed positive significant correlations with scores in arousal, whereas ratings for the angry, sad, fearful, and disgusting words showed significant negative correlations with their ratings on the valence variable. Also, scores for words denoting happy concepts showed a positive correlation with their valence scores. These findings suggest a 
Table 3 Correlations between the dimensions of valence (Val), arousal (Aro), and concreteness (Con) and the discrete emotions of happiness (Hap), anger (Ang), sadness (Sad), fear (Fea), and disgust (Dis), as well

\begin{tabular}{|c|c|c|c|c|c|c|c|c|c|c|c|}
\hline & Val & Aro & Con & Hap & Ang & $\mathrm{Sad}$ & Fea & Dis & Freq & Lett & Syll \\
\hline Valence & 1 & & & & & & & & & & \\
\hline Arousal & $-.15^{* *}$ & 1 & & & & & & & & & \\
\hline Concreteness & $-.11^{* *}$ & $.14^{* *}$ & 1 & & & & & & & & \\
\hline Happiness & $.93^{* *}$ & .07 & -.04 & 1 & & & & & & & \\
\hline Anger & $-.81^{* *}$ & $.46^{* *}$ & $.14^{* *}$ & $-.64^{* *}$ & 1 & & & & & & \\
\hline Sadness & $-.79^{* *}$ & $.33^{* *}$ & $.19^{* *}$ & $-.62^{* *}$ & .33 & 1 & & & & & \\
\hline Fear & $-.73^{* *}$ & $.53^{* *}$ & $.17^{* *}$ & $-.57^{* *}$ & $.77^{* *}$ & $.81^{* *}$ & 1 & & & & \\
\hline Disgust & $-.75^{* *}$ & $.33^{* *}$ & $.25^{* *}$ & $-.60^{* *}$ & $.76^{* *}$ & $.63^{* *}$ & $.60^{* *}$ & 1 & & & \\
\hline Frequency & $.15^{* *}$ & $-.13^{* *}$ & -.17 & $.13^{* *}$ & $-.15^{* *}$ & $-.10^{*}$ & $-.10^{*}$ & $-.13^{* *}$ & 1 & & \\
\hline Length (letters) & -.07 & $.14^{* *}$ & -.04 & -.05 & $.11^{* *}$ & $.12^{* *}$ & $.11^{*}$ & .07 & $-.28^{* *}$ & 1 & \\
\hline Length (syllables) & -.07 & $.10^{*}$ & -.04 & -.05 & .08 & .08 & .07 & .08 & $-.26^{* *}$ & $.84^{* *}$ & 1 \\
\hline
\end{tabular}

${ }^{*} p<.005,{ }^{* *} p<.001$

close relationship between ratings in the affective dimensions and emotional discrete categories.

Overall, these results highlight the importance of considering ratings for both affective dimensions and categories when designing experiments, since the ratings allow researchers to explore language in relation to both basic emotion and dimensional models (Strauss \& Allen, 2008). In this sense, it has been argued that whereas a dimensional approximation can portray broad features of emotion, and the categorical perspective can capture more discrete emotional aspects, both views can be used in combination to draw a comprehensive picture of affective language processing (Stevenson et al., 2007).

Relationship between affective and psycholinguistic variables

Pearson correlations were calculated between the subjective and objective psycholinguistic variables-frequency, word length (both number of letters and number of syllables), and concreteness - and the emotional variables (see Table 3 ). Concreteness scores showed significant positive correlations with ratings in arousal, indicating that more arousing words were rated as being more concrete. In contrast, a significant negative correlation between valence and concreteness scores was observed, suggesting that words rated as being more positive were also rated as being more abstract (e.g., creativo,

Table 4 Correlations between every discrete emotion and the affective dimensions of valence and arousal

\begin{tabular}{lccccc}
\hline & Happy & Angry & Sad & Fearful & Disgusting \\
\hline Arousal & $.48^{* *}$ & $.67^{* *}$ & $.35^{* *}$ & $.57^{* *}$ & $-.76^{* *}$ \\
Valence & $.86^{* *}$ & $-.73^{* *}$ & $-.57^{* *}$ & $-.70^{* *}$ & $.51^{*}$ \\
\hline
\end{tabular}

${ }^{*} p<.005,{ }^{* *} p<.001$ as correlations with word frequency from the LEXESP (Freq), number of letters (Lett), and number of syllables (Syll) 
words were quite frequent and more abstract, whereas highly arousing words were less frequent, longer, and more concrete. Some of the patterns of correlations that we observed between affective dimensions and psycholinguistic variables matched previous findings (e.g., Citron et al., 2014; Gilet, Grühn, Studer, \& Labouvie-Vief, 2012; Monnier \& Syssau, 2014; Võ et al., 2009; Warriner et al., 2013), whereas they were incompatible in some respects with those reported in other studies (e.g., Ferré et al., 2012; Moors et al., 2013). Divergences can be attributed to differences in stimulus sets, language characteristics, and/or sample peculiarities. Nevertheless, the results from the present and other studies indicate that psycholinguistic variables should receive full consideration when designing investigations that manipulate affective variables in linguistic materials. This may be of particular interest for those studies investigating the processing of affective words from a discreteemotion perspective, since there have been no prior reports of a relationship between emotional categories and psycholinguistic variables such as concreteness or word frequency.

\section{Gender differences}

In order to explore the existence of gender differences in word ratings for both emotional dimensions and categories, we examined the associations between males' and females' scores. High correlations were found between men and women for the arousal $(r=.66)$ and valence $(r=.83)$ dimensions (both $p$ s $<$ $.001)$. Also, the ratings of men and women were highly correlated for the happy $(r=.90)$, angry $(r=.83)$, sad $(r=.77)$, fearful $(r=.81)$, and disgust $(r=.80)$ emotional categories (all $p \mathrm{~s}<.001)$. These findings suggest that males and females agreed closely when they scored the words in both dimensional and discrete emotions, which resembles prior reports in the literature (e.g., Monnier \& Syssau, 2014; Redondo et al., 2007; Soares et al., 2012).

We conducted additional analyses to compare the average emotional ratings by male and female participants by means of two-tailed paired $t$ tests. Regarding the affective dimensions, we found that males gave higher mean valence scores than did females $[M \mathrm{~s}=4.90$ and $4.78, S D \mathrm{~s}=2.17$ and 2.20 , respectively; $t(874)=-2.78, p<.01]$, indicating that men assessed words as being more positive than did women. This finding parallels those results reported in some studies (e.g., Monnier \& Syssau, 2014; Montefinese et al., 2014; Soares et al., 2012), whereas it contradicts the results of other studies (Bradley \& Lang, 1999; Redondo et al., 2007). Gender differences in valence ratings may be attributed to the existence of cognitive differences between the sexes or to differences in response styles (Belleza, Greenwald, \& Banaji, 1986), although the inconsistency of prior reports suggest that some caution is needed when interpreting gender differences in affective word ratings. The same line of reasoning may be applied to the analysis of arousal scores. In line with prior reports (e.g.,
Gilet et al., 2012; Redondo et al., 2007), we found no differences between males' and females' ratings on the arousal dimension $[M \mathrm{~s}=5.52$ and $5.60, S D \mathrm{~s}=1.49$ and 2.17 , respectively; $t(874)=1.84, p>.05]$. However, higher mean arousal ratings have been observed in some studies (e.g., Soares et al., 2012; Söderholm, Häyry, Laine, \& Karrasch, 2013).

With respect to discrete categories, men reported significantly higher ratings for anger $[M \mathrm{~s}=1.91$ and $1.86, S D \mathrm{~s}=$ 0.99 and 0.97 , respectively; $t(874)=-2.32, p<.05]$ and fear $[M \mathrm{~s}=2.12$ and $2.06, S D \mathrm{~s}=0.98$ and 1.00 , respectively; $t(874)$ $=-3.16, p<.01]$, whereas we did not observe differences between males and females for happiness $[M \mathrm{~s}=2.28$ and $2.26, S D \mathrm{~s}=1.25$ and 1.25 , respectively; $t(874)=-0.89, p>$ $.05]$, sadness $[M \mathrm{~s}=1.99$ and $1.95, S D \mathrm{~s}=0.98$ and 0.99 , respectively; $t(874)=-1.82, p>.05]$, or disgust $[M \mathrm{~s}=1.70$ and $1.70, S D \mathrm{~s}=0.80$ and 0.82 , respectively; $t(874)=-0.55, p$ $>.05]$. Although gender effects on words belonging to distinct discrete emotional categories have not previously been explored, the present data suggest that differences between men and women are noticeable in those negative emotional categories - anger and fear - that elicit rapid social/affective reactions (as compared to the sadness or disgust categories).

Taken together, our findings show that some gender differences in the assessment of affective words exist at both the dimensional and discrete-emotion levels. This is in agreement with prior findings using a variety of experimental paradigms, which have pointed to the existence of differences in the processing of emotional language between men and women (e.g., Hamann \& Canli, 2004; Smith \& Waterman, 2005). However, the high consistency between males' and females' affective ratings also suggests that the emotional experiences of men and women are quite analogous, at least in several respects.

\section{Conclusions}

Norm lists in which words are rated according to discrete emotions are not common, and those that have characterized in terms of both discrete emotions and emotional dimensions have been rare. At the present time, such corpora have only been available in English (Stevenson et al., 2007; Strauss \& Allen, 2008) and German (Briesemeister et al., 2011b). In the present study, we have provided additional data from a set of 875 Spanish words, allowing researches to control their stimuli with regard to discrete and dimensional affective variables. Thus, the MADS may be a suitable tool to investigate interactions between dimensional and discrete-emotion information. This may be especially relevant for theoretical proposals that pursue the objective of integrating discrete and dimensional conceptions into a unified theoretical approach (e.g., the core affect theory, Russell, 2003; see also Panksepp \& Watt, 2011, for an alternative, integrative account). Along these lines, recent behavioral and ERP evidence is suggesting 
that discrete emotions may serve as a basis for subsequent dimensional appraisal processes alone (Briesemeister et al., 2014), a finding that cannot easily be interpreted in terms of traditional discrete-emotion or affective-dimension theories. As has been pointed out, "more research will have to be done to fully understand the interplay of the various dimensions constituting the affective space within and across different languages" (Schmidtke et al., 2014, p. 1116). These additional efforts may benefit from norm lists providing stimuli rated for several emotional variables and in other languages in which they were not currently available, as is the case for the present database.

Author Note This work was supported by Grant No. PSI2012-37535 from the Ministerio de Economía y Competitividad (MINECO) of Spain and Grant No. 2012V/PUNED/0009 from the UNED.

\section{Appendix}

The following texts are the instructions given to the participants, with their corresponding English translations:

\section{General instructions}

A continuación se presenta un listado de palabras en el que te pedimos que por favor las evalúes según una serie de criterios:

- El grado de abstracción/concreción se refiere a cómo te resulta de abstracto o concreto el concepto al que se refiere cada palabra. Por ejemplo, "libertad" es un concepto abstracto, mientras que "vaso" es un concepto concreto.

- La activación hace referencia al nivel de relajación/ activación que genera una palabra.

- La valencia es el grado en el que el concepto que designa una palabra hace referencia algo que te resulta negativo (aversivo) o positivo (atractivo).

- Por último, te pedimos que puntúes cada una de las palabras en las 5 categorías emocionales que se presentan (alegría, ira, tristeza, miedo, asco).

Selecciona sólo una respuesta por cada palabra y recuerda que no hay respuestas correctas o incorrectas.

You will be presented with a list of words. We kindly ask you to rate them according to the following criteria:

- The level of abstraction/concreteness refers to how abstract or concrete you think that the concept is. For example, "freedom" is an abstract concept, while "glass" is a concrete one.
- Arousal refers to the level of relaxation/excitation that the word generates.

- Valence is the degree to which the concept expressed by the word refers to something negative (aversive) or positive (attractive).

- Finally, we ask you to score each word in the 5 emotional categories given (happiness, anger, sadness, fear, disgust).

Choose only one answer for each word and remember that there are no right or wrong answers.

Instructions for the dimensional ratings

A continuación te pedimos que por favor nos indiques el nivel de valencia, activación y abstracción / concreción de los conceptos a los que hacen referencia las siguientes palabras.

La valencia es el grado en el que el concepto que designa una palabra hace referencia algo que te resulta negativo (aversivo) o positivo (atractivo). Valora las palabras en una escala del 1 al 9, siendo 1 "muy negativo" y 9 "muy positivo." Este dibujo es una representación de la escala.

La activación hace referencia al nivel de relajación/ activación que genera una palabra. Usa una escala del 1 al 9, siendo 1 "muy poca activación" (algo muy relajante) y 9 "mucha activación" (el máximo valor de activación generada). Este dibujo es una representación de la escala.

El grado de abstracción/concreción de una palabra se refiere al grado de especificidad de su contenido. Por ejemplo, la palabra "objeto" es poco concreta porque su contenido es compatible con una familia muy amplia y variada de objetos diferentes, mientras que la palabra "percha" es bastante concreta porque contenido es compatible con una gama muy restringida de objetos.

Valora las palabras en una escala de 1 a 9, siendo 1

"muy abstracto" y 9 "muy concreto."

We kindly ask you to indicate the level of valence, arousal and abstraction/concreteness of the concepts denoted by the following words.

Valence is the degree to which the concept refers to something that you feel that is negative (aversive) or positive (attractive). Rate the words on a scale of 1 to 9 , with a score of 1 being "very negative" and 9 being "very positive." Below you have a pictorial representation of the scale.

Arousal refers to the level of relaxation/excitation that the word generates. Use a scale of 1 to 9 , with a score of 1 being "very low arousal" (something very relaxing/calming) and 9 "very high arousal" (the maximum level of excitation). Below you have a pictorial representation of the scale. 
The level of abstraction/concreteness refers to the extent to which it has a specific content. For example, the word "object" has a low level of concreteness because its content can include a varied set of different objects. However, the word "hanger" has a high level of concreteness because its content can be applied to a very restricted set of objects. Make your rating using a scale of 1 to 9 , with 1 being "very abstract" and 9 being "very concrete."

Instructions for the categorical ratings

A continuación te pedimos que por favor puntúes cada una de las palabras en las 5 categorías emocionales que se presentan: alegría, ira, tristeza, miedo y asco.

Por favor, responde a todas las palabras del cuestionario marcando la puntuación que estimes en una escala de 1 a 5, siendo 1 "nada en absoluto" y 5 "extremadamente."

No olvides responder a cada una de las categorías emocionales.

We kindly ask you to rate each of the following words according to the 5 emotional categories presented: happiness, anger, sadness, fear and disgust.

Please, answer to all of the words in the questionnaire by selecting the score that you consider appropriate on a scale of 1 to 5 , with 1 being "nothing at all" and 5 "extremely."

Do not forget to answer to each of the five emotional categories.

\section{References}

Algom, D., Chajut, E., \& Lev, S. (2004). A rational look at the emotional Stroop phenomenon: A generic slowdown, not a Stroop effect. Journal of Experimental Psychology: General, 133, 323-338. doi: 10.1037/0096-3445.133.3.323

Barrett, L. F., \& Russell, J. A. (1999). The structure of current affect controversies and emerging consensus. Current Directions in Psychological Science, 8, 10-14.

Bauer, L. M., \& Altarriba, J. (2008). An investigation of sex differences in word ratings across concrete, abstract, and emotion words. Psychological Record, 58, 465-474.

Bellezza, F. S., Greenwald, A. G., \& Banaji, M. R. (1986). Words high and low in pleasantness as rated by male and female college students. Behavior Research Methods, Instruments, \& Computers, 18, 299-303. doi:10.3758/BF03204403

Bertels, J., Kolinsky, R., \& Morais, J. (2009). Norms of emotional valence, arousal, threat value and shock value for 80 spoken French words: Comparison between neutral and emotional tones of voice. Psychologica Belgica, 49, 19-40.

Bradley, M. M., \& Lang, P. J. (1994). Measuring emotion: The SelfAssessment Manikin and the semantic differential. Journal of Behavioral Therapy and Experimental Psychiatry, 25, 49-59. doi: 10.1016/0005-7916(94)90063-9
Bradley, M. M., \& Lang, P. J. (1999). Affective norms for English words (ANEW): Stimuli, instruction manual and affective ratings (Technical Report No. C-1, pp. 1-45). Gainesville, FL: University of Florida, NIMH Center for Research in Psychophysiology.

Briesemeister, B. B., Kuchinke, L., \& Jacobs, A. M. (2011a). Discrete emotion effects on lexical decision response times. PLOS ONE, 6, e23743. doi:10.1371/journal.pone.0023743

Briesemeister, B. B., Kuchinke, L., \& Jacobs, A. M. (2011b). Discrete emotion norms for nouns: Berlin Affective Word List (DENNBAWL). Behavior Research Methods, 43, 441-448. doi:10.3758/ s13428-011-0059-y

Briesemeister, B. B., Kuchinke, L., \& Jacobs, A. M. (2014). Emotion word recognition: Discrete information effects first, continuous later? Brain Research, 1564, 62-71. doi:10.1016/j.brainres.2014.03. 045

Burke, L. A., \& James, K. E. (2006). Using on-line surveys for primary research data collection: Lessons from the field. International Journal of Innovation and Learning, 3, 16-30.

Campos, A., \& Astorga, V. M. (1988). Abstractness and emotional values for French and Spanish words. Perceptual and Motor Skills, 66, 649-650. doi:10.2466/pms.1988.66.2.649

Citron, F. M. M. (2012). Neural correlates of written emotion word processing: A review of recent electrophysiological and hemodynamic neuroimaging studies. Brain and Language, 122, 211-226. doi:10. 1016/j.bandl.2011.12.007

Citron, F. M. M., Weekes, B. S., \& Ferstl, E. C. (2014). How are affective word ratings related to lexico-semantic properties? Evidence from the Sussex Affective Word List. Applied PsychoLinguistics, 35, 313-331. doi:10.1017/S0142716412000409

Couper, M. P. (2000). Web surveys: A review of issues and approaches. Public Opinion Quarterly, 64, 464-494.

Dijksterhuis, A., \& Aarts, H. (2003). On wildebeests and humans: The preferential detection of negative stimuli. Psychological Science, 14, $14-18$.

Eilola, T. M., \& Havelka, J. (2010). Affective norms for 210 British English and Finnish nouns. Behavior Research Methods, 42, 134 140. doi:10.3758/BRM.42.1.134

Eimer, M., \& Holmes, A. (2002). An ERP study on the time course of emotional face processing. NeuroReport, 13, 427-431.

Eimer, M., Holmes, A., \& McGlone, F. P. (2003). The role of spatial attention in the processing of facial expression: An ERP study of rapid brain responses to six basic emotions. Cognitive, Affective, \& Behavioral Neuroscience, 3, 97-110. doi:10.3758/CABN.3.2.97

Ekman, P. (1992). An argument for basic emotions. Cognition and Emotion, 6, 169-200.

Ekman, P. (1999). Facial expressions. In T. Dalgleish \& M. J. Power (Eds.), Handbook of cognition and emotion (pp. 301-320). New York, NY: Wiley.

Estes, Z., \& Adelman, J. S. (2008). Automatic vigilance for negative words in lexical decision and naming: Comment on Larsen, Mercer, and Balota (2006). Emotion, 8, 441-444.

Estes, Z., \& Verges, M. (2008). Freeze or flee? Negative stimuli elicit selective responding. Cognition, 108, 557-565.

Ferré, P., Guasch, M., Moldovan, C., \& Sánchez-Casas, R. (2012). Affective norms for 380 Spanish words belonging to three different semantic categories. Behavior Research Methods, 44, 395-403. doi: 10.3758/s13428-011-0165-x

Ferstl, E., Rinck, M., \& von Cramon, D. Y. (2005). Emotional and temporal aspects of situation model processing during text comprehension: An event-related fMRI study. Journal of Cognitive Neuroscience, 17, 724-739.

Fraga, I., Piñeiro, A., Acuña-Fariña, C., Redondo, J., \& García-Orza, J. (2012). Emotional nouns affect attachment decisions in sentence completion tasks. Quarterly Journal of Experimental Psychology, $65,1740-1759$. 
Gilet, A.-L., Grühn, D., Studer, J., \& Labouvie-Vief, G. (2012). Valence, arousal, and imagery ratings for 835 French attributes by young, middle-aged, and older adults: The French Emotional Evaluation List (FEEL). European Review of Applied Psychology, 62, 173181. doi:10.1016/j.erap.2012.03.003

González-Villar, A. J., Triñanes, Y., Zurrón, M., \& Carrillo-de-la-Peña, M. T. (2014). Brain processing of task-relevant and task-irrelevant emotional words: An ERP study. Cognitive, Affective, \& Behavioral Neuroscience, 14, 939-950. doi:10.3758/s13415-013-0247-6

Grühn, D., \& Smith, J. (2008). Characteristics for 200 words rated by young and older adults: Age-dependent evaluations of German adjectives (AGE). Behavior Research Methods, 40, 1088-1097. doi: 10.3758/BRM.40.4.1088

Hamann, S., \& Canli, T. (2004). Individual differences in emotion processing. Current Opinion in Neurobiology, 14, 233-238.

Herbert, C., Junghofer, M., \& Kissler, J. (2008). Event related potentials to emotional adjectives during reading. Psychophysiology, 45, 487498. doi:10.1111/j.1469-8986.2007.00638.x

Hinojosa, J. A., Albert, J., Fernández-Folgueiras, U., Santaniello, G., López-Bachiller, C., Sebastián, M., ... Pozo, M. A. (2014). Effects of negative content on the processing of gender information: An event-related potential study. Cognitive, Affective, \& Behavioral Neuroscience, 14, 1286-1299. doi:10.3758/s13415-014-0291-x

Hinojosa, J. A., Albert, J., López-Martín, S., \& Carretié, L. (2014b). Temporospatial analysis of explicit and implicit processing of negative content during word comprehension. Brain and Cognition, 87, 109-121. doi:10.1016/j.bandc.2014.03.008

Hinojosa, J. A., Carretié, L., Valcárcel, M. A., Méndez-Bértolo, C., \& Pozo, M. A. (2009). Electrophysiological differences in the processing of affective information in words and pictures. Cognitive, Affective, \& Behavioral Neuroscience, 9, 173-189. doi:10.3758/ CABN.9.2.173

Hinojosa, J. A., Méndez-Bértolo, C., Carretié, L., \& Pozo, M. A. (2010a). Emotion modulates language production during covert picture naming. Neuropsychologia, 48, 1725-1734.

Hinojosa, J. A., Méndez-Bértolo, C., \& Pozo, M. A. (2012). High arousal words influence subsequent processing of neutral information: Evidence from event-related potentials. International Journal of Psychophysiology, 86, 143-151.

Hinojosa, J. A., Méndez-Bértolo, C., \& Pozo, M. A. (2010b). Looking at emotional words is not the same as reading emotional words: Behavioral and neural correlates. Psychophysiology, 47, 748-757.

Hinojosa, J. A., Mercado, F., Albert, J., Barjola, P., Peláez, I., VillalbaGarcía, C., \& Carretié, L. (2015). Neural correlates of an early attentional capture by positive distractor words. Frontiers in Psychology, 6, 24. doi:10.3389/fpsyg.2015.00024

Hofmann, M. J., Kuchinke, L., Tamm, S., Võ, M. L.-H., \& Jacobs, A. M. (2009). Affective processing within 1/10th of a second: High arousal is necessary for early facilitative processing of negative but not positive words. Cognitive, Affective, \& Behavioral Neuroscience, 9, 389-397. doi:10.3758/9.4.389

Holt, D. J., Lynn, S. K., \& Kuperberg, G. R. (2009). Neurophysiological correlates of comprehending emotional meaning in context. Journal of Cognitive Neuroscience, 21, 2245-2262. doi:10.1162/jocn.2008. 21151

Isenberg, N., Silbersweig, D., Engelien, A., Emmerich, S., Malavade, K., Beattie, B. A., ... Stern, E. (1999). Linguistic threat activates the human amygdala. Proceedings of the National Academy of Sciences, 96, 10456-10459.

Janschewitz, K. (2008). Taboo, emotionally valenced, and emotionally neutral word norms. Behavior Research Methods, 40, 1065-1074. doi:10.3758/BRM.40.4.1065

Kanske, P., \& Kotz, S. A. (2007). Concreteness in emotional words: ERP evidence from a hemifield study. Brain Research, 1148, 138-148. doi:10.1016/j.brainres.2007.02.044
Kanske, P., \& Kotz, S. A. (2010). Leipzig Affective Norms for German: A reliability study. Behavior Research Methods, 42, 987-991. doi: 10.3758/BRM.42.4.987

Kissler, J., Assadollahi, R., \& Herbert, C. (2006). Emotional and semantic networks in visual word processing: Insights from ERP studies. Progress in Brain Research, 156, 147-183.

Kissler, J., \& Herbert, C. (2013). Emotion, Etmnooi, or Emitoon?Faster lexical access to emotional than to neutral words during reading. Biological Psychology, 92, 464-479. doi:10.1016/j.biopsycho. 2012.09.004

Kissler, J., Herbert, C., Peyk, P., \& Junghofer, M. (2007). Buzzwords: Early cortical responses to emotional words during reading. Psychological Science, 18, 475-480. doi:10.1111/j.1467-9280. 2007.01924.x

Kousta, S.-T., Vigliocco, G., Vinson, D. P., Andrews, M., \& Del Campo, E. (2011). The representation of abstract words: Why emotion matters. Journal of Experimental Psychology: General, 140, 14-34. doi: $10.1037 / \mathrm{a} 0021446$

Kousta, S.-T., Vinson, D. P., \& Vigliocco, G. (2009). Emotion words, regardless of polarity, have a processing advantage over neutral words. Cognition, 112, 473-481. doi:10.1016/j.cognition.2009.06. 007

Kristensen, C. H., Gomes, C. F. D. A., Justo, A. R., \& Vieira, K. (2011). Brazilian norms for the affective norms for English words. Trends in Psychiatry and Psychotherapy, 33, 135-146.

Kuchinke, L., Jacobs, A. M., Grubich, C., Võ, M. L.-H., Conrad, M., \& Herrmann, M. (2005). Incidental effects of emotional valence in single word processing: An fMRI study. Neurolmage, 28, 10221032.

Kuperman, V., Estes, Z., Brysbaert, M., \& Warriner, A. B. (2014). Emotion and language: Valence and arousal affect word recognition. Journal of Experimental Psychology: General, 14, 1065-1080.

Lang, P. J., Bradley, M. M., \& Cuthbert, B. N. (1990). Emotion, attention, and the startle reflex. Psychological Review, 97, 377-395. doi:10. 1037/0033-295X.97.3.377

Martín-Loeches, M., Fernández, A., Schacht, A., Sommer, W., Casado, P., Jiménez-Ortega, L., \& Fondevila, S. (2012). The influence of emotional words on sentence processing: Electrophysiological and behavioral evidence. Neuropsychologia, 50, 3262-3272. doi:10. 1016/j.neuropsychologia.2012.09.010

Méndez-Bértolo, C., Pozo, M. A., \& Hinojosa, J. A. (2011a). Early effects of emotion on word immediate repetition priming: Electrophysiological and source localization evidence. Cognitive, Affective, \& Behavioral Neuroscience, 11, 652-665. doi:10.3758/ s13415-011-0059-5

Méndez-Bértolo, C., Pozo, M. A., \& Hinojosa, J. A. (2011b). Word frequency modulates the processing of emotional words: Convergent behavioral and electrophysiological data. Neuroscience Letters, 494, $250-254$

Monnier, C., \& Syssau, A. (2014). Affective norms for French words (FAN). Behavior Research Methods, 46, 1128-1137. doi:10.3758/ s13428-013-0431-1

Montefinese, M., Ambrosini, E., Fairfield, B., \& Mammarella, N. (2014). The adaptation of the Affective Norms for English Words (ANEW) for Italian. Behavior Research Methods, 46, 887-903. doi:10.3758/ s13428-013-0405-3

Moors, A., De Houwer, J., Hermans, D., Wanmaker, S., van Schie, K., Van Harmelen, A. L., \& Brysbaert, M. (2013). Norms of valence, arousal, dominance, and age of acquisition for 4,300 Dutch words. Behavior Research Methods, 45, 169-177. doi:10.3758/s13428012-0243-8

Nakic, M., Smith, B. W., Busis, S., Vythilingam, M., \& Blair, R. J. R. (2006). The impact of affect and frequency on lexical decision: The role of the amygdala and inferior frontal cortex. NeuroImage, 31, $1752-1761$. 
Palazova, M., Mantwill, K., Sommer, W., \& Schacht, A. (2011). Are effects of emotion in single words non-lexical? Evidence from event-related brain potentials. Neuropsychologia, 49, 2766-2775. doi:10.1016/j.neuropsychologia.2011.06.005

Palazova, M., Sommer, W., \& Schacht, A. (2013). Interplay of emotional valence and concreteness in word processing: An event-related potential study with verbs. Brain and Language, 125, 264-271.

Panksepp, J. (1998). Affective neuroscience: The foundations of human and animal emotions. New York, NY: Oxford University Press.

Panksepp, J., \& Watt, D. (2011). What is basic about basic emotions? Lasting lessons from affective neuroscience. Emotion Review, 3, 387-396.

Pérez-Dueñas, C., Acosta, A., Megías, J. L., \& Lupiáñez, J. (2010). Evaluación de las dimensiones de valencia, activación, frecuencia subjetiva de uso y relevancia para la ansiedad, la depresión y la ira de 238 sustantivos en una muestra universitaria. Psicológica, 31, 241273.

Redondo, J., Fraga, I., Comesaña, M., \& Perea, M. (2005). Estudio Normativo del valor afectivo de 478 palabras españolas. Psicológica, 26, 317-326.

Redondo, J., Fraga, I., Padrón, I., \& Comesaña, M. (2007). The Spanish adaptation of ANEW (Affective Norms for English Words). Behavior Research Methods, 39, 600-605. doi:10.3758/ BF03193031

Robinson, M. D., Storbeck, J., Meier, B. P., \& Kirkeby, B. S. (2004). Watch out! That could be dangerous: Valence-arousal interactions in evaluative processing. Personality and Social Psychology Bulletin, 30, 1472-1484. doi:10.1177/0146167204266647

Russell, J. A. (1980). A circumplex model of affect. Journal of Personality and Social Psychology, 39, 1161.

Russell, J. A. (2003). Core affect and the psychological construction of emotion. Psychological Review, 110, 145-172. doi:10.1037/0033295X.110.1.145

Schacht, A., \& Sommer, W. (2009). Time course and task dependence of emotion effects in word processing. Cognitive, Affective, \& Behavioral Neuroscience, 9, 28-43. doi:10.3758/CABN.9.1.28

Schmidtke, D. S., Schröder, T., Jacobs, A. M., \& Conrad, M. (2014). ANGST: Affective norms for German sentiment terms, derived from the affective norms for English words. Behavior Research Methods, 46, 1108-1118. doi:10.3758/s13428-013-0426-y

Scott, G. G., O’Donnell, P. J., Leuthold, H., \& Sereno, S. C. (2009). Early emotion word processing: Evidence from event-related potentials. Biological Psychology, 80, 95-104. doi:10.1016/j.biopsycho.2008. 03.010

Scott, G. G., O’Donnell, P. J., \& Sereno, S. C. (2012). Emotion words affect eye fixations during reading. Journal of Experimental Psychology: Learning, Memory, and Cognition, 38, 783-792. doi: 10.1037/a0027209

Scott, G. G., O’Donnell, P. J., \& Sereno, S. C. (2014). Emotion words and categories: Evidence from lexical decision. Cognitive Processing, $15,209-215$.

Sebastián-Gallés, N., Martí, M. A., Carreiras, M., \& Cuetos, F. (2000). LEXESP: Una base de datos informatizado del español [CD-ROM]. Barcelona, Spain: Ediciones de la Universitat de Barcelona.
Silva, C., Montant, M., Ponz, A., \& Ziegler, J. C. (2012). Emotions in reading: Disgust, empathy and the contextual learning hypothesis. Cognition, 125, 333-338. doi:10.1016/j.cognition.2012.07.013

Smith, P., \& Waterman, M. (2005). Sex differences in processing aggression words using the emotional Stroop task. Aggressive Behavior, 31, 271-282.

Soares, A. P., Comesaña, M., Pinheiro, A. P., Simões, A., \& Frade, C. S. (2012). The adaptation of the Affective Norms for English words (ANEW) for European Portuguese. Behavior Research Methods, 44, 256-269. doi:10.3758/s13428-011-0131-7

Söderholm, C., Häyry, E., Laine, M., \& Karrasch, M. (2013). Valence and arousal ratings for 420 Finnish nouns by age and gender. PLOS ONE, 8, e72859. doi:10.1371/journal.pone.0072859

Stevenson, R. A., \& James, T. W. (2008). Affective auditory stimuli: Characterization of the International Affective Digitized Sounds (IADS) by discrete emotional categories. Behavior Research Methods, 40, 315-321. doi:10.3758/BRM.40.1.315

Stevenson, R. A., Mikels, J. A., \& James, T. W. (2007). Characterization of the affective norms for English words by discrete emotional categories. Behavior Research Methods, 39, 1020-1024. doi:10.3758/ BF03192999

Straube, T., Sauer, A., \& Miltner, W. H. (2011). Brain activation during direct and indirect processing of positive and negative words. Behavioural Brain Research, 222, 66-72.

Strauss, G. P., \& Allen, D. N. (2008). Emotional intensity and categorisation ratings for emotional and nonemotional words. Cognition and Emotion, 22, 114-133.

Syssau, A., \& Monnier, C. (2009). Children's emotional norms for 600 French words. Behavior Research Methods, 41, 213-219. doi:10. 3758/BRM.41.1.213

Vasa, R. A., Carlino, A. R., London, K., \& Min, C. (2006). Valence ratings of emotional and non-emotional words in children. Personality and Individual Differences, 41, 1169-1180.

Vigliocco, G., Kousta, S. T., Della Rosa, P. A., Vinson, D. P., Tettamanti, M., Devlin, J. T., \& Cappa, S. F. (2014). The neural representation of abstract words: The role of emotion. Cerebral Cortex, 24, 1767 1777. doi:10.1093/cercor/bht025

Võ, M. L.-H., Conrad, M., Kuchinke, L., Urton, K., Hofmann, M. J., \& Jacobs, A. M. (2009). The Berlin Affective Word List Reloaded (BAWL-R). Behavior Research Methods, 41, 534-538. doi:10. 3758/BRM.41.2.534

Võ, M. L.-H., Jacobs, A. M., \& Conrad, M. (2006). Cross-validating the Berlin Affective Word List. Behavior Research Methods, 38, 606 609. doi:10.3758/BF03193892

Warriner, A. B., Kuperman, V., \& Brysbaert, M. (2013). Norms of valence, arousal, and dominance for 13,915 English lemmas. Behavior Research Methods, 45, 1191-1207. doi:10.3758/ s13428-012-0314-x

Yao, Z., \& Wang, Z. (2014). Concreteness of positive word contributions to affective priming: An ERP study. International Journal of Psychophysiology, 93, 275-282. 